\title{
A MEDIAÇÃO AMBIENTAL INTERNACIONAL E A INTERAÇÃO ENTRE PAZ, DESENVOLVIMENTO E PROTEÇÃO AMBIENTAL.
}

\author{
Adriana Machado Yaghsisian* \\ Simone Alves Cardoso**
}

\begin{abstract}
Resumo: A evolução, transformação e riscos ambientais levam a uma preocupação crescente com o processo de tomada de decisão em relação aos meios ou instrumentos necessários a serem aplicados na resolução dos conflitos ambientais. Esses instrumentos precisam estar afinados com a atual dinâmica de estruturação da sociedade em rede e pós-moderna. Para tanto, pretendese analisar como a mediação ambiental internacional pode contribuir para apresentar uma resposta para a questão ambiental, que permita a construção de um ambiente de paz, levando em conta os contextos locais de cada conflito, de cada indivíduo, grupo ou sociedade afetada, bem como seus aspectos culturais.
\end{abstract}

Palavras chaves: Mediação ambiental internacional, paz, desenvolvimento, meio-ambiente, conflitos

\section{INTERNATIONAL ENVIRONMENTAL MEDIATION AND THE INTERACTION BETWEEN PEACE, DEVELOPMENT AND ENVIRONMENT PROTECTION.}

\footnotetext{
* Possui graduação em Pedagogia pela Universidade Santa Cecilia (1990), graduação em Direito pela Universidade Católica de Santos (1994), mestrado em Direitos Difusos e Coletivos pela Universidade Metropolitana de Santos (2004) e doutorado em Direito Ambiental Internacional pela Universidade Católica de Santos. Integra o grupo de pesquisa em Energia e Meio Ambiente, do grupo de pesquisa em Resolução de Conflitos Socioambientais e do grupo de pesquisa em Direitos Humanos, da Pós-gradução Mestrado e Doutorado da Unisantos. Possui capacitação para conciliação e mediação, conferida pelo EPM/SP, com atividade no anexo do Juizado Especial Cível da Unisantos. Atualmente é professora do curso de Direito da Universidade Católica de Santos, além de atuar como instrutora do Curso de Extensão, de Capacitação de Conciliadores e Mediadores da Unisantos certificada pelo TJ/SP. Mediadora da Câmara de Mediação de conflitos Socioambientais, Urbanísticos e Empresariais da Unisantos. E-mail: machado4@gmail.com

** Doutora em Direito Ambiental Internacional, mestre em Direito Urbanístico pela Pontifícia Universidade Católica de São Paulo (2004) e graduada em Direito pela Universidade de Franca (2000). Professora na graduação da Faculdade de Direito da Universidade Católica de Santos. Mediadora certificada pela Escola Paulista da Magistratura, Coordenadora do Juizado Especial Civil da Universidade Católica de Santos, núcleo de extensão em parceria com o TJ/SP e Coordenadora do Curso de Extensão de Capacitação de Conciliadores e Mediadores da Unisantos, credenciado no TJ/SP. Mediadora da Câmara de Mediação de conflitos Socioambientais, Urbanísticos e Empresariais da Unisantos. Integra o grupo de pesquisa em Resolução de Conflitos Socioambientais e o grupo de Energia e Meio Ambiente do programa de Pós-gradução Mestrado e Doutorado da Unisantos. Têm experiência na área de Direito Urbanístico, Ambiental Internacional, Direito Consumidor e Mediação. E-mail: sacardoso75@gmail.com.
} 
Abstract: Evolution, transformation and environmental risks lead to growing concern about the decision-making process regarding the means or instruments needed to be applied in solving environmental conflicts. These instruments need to be in tune with the current dynamics of structuring the networked and postmodern society. In this sense, this article is intended to analyze how international environmental mediation can contribute to presenting a response to the environmental issue, allowing the construction of a peaceful environment, taking into account the local contexts of each conflict, individual, group or society as well as its cultural aspects.

Keywords: International environmental mediation, peace, development, environment, conflicts.

\section{Introdução}

Uma questão que se apresenta como um problema a ser enfrentado e superado pelo direito internacional é a manutenção da paz. Criar condições para paz implica desconstruir estruturas, situações e relações que causem conflitos e focar na construção de estruturas, situações e relações que sustentam a paz.

Dada a importância do tema para o direito ambiental internacional, a paz foi incluída como um dos objetivos da agenda 2030 para o desenvolvimento sustentável (ODS). Segundo o ODS 16, os Estados devem se empenhar em promover sociedades pacíficas e inclusivas, o que implica garantir a tomada de decisões responsáveis, participativas e representativas em todos os níveis.

Com o fenômeno da globalização, algumas questões ficaram mais evidentes e a temática ambiental tem colocado à prova a atuação dos Estados, no sentido de promover a paz, independentemente de seus sistemas políticos, econômicos e culturais.

A extensão transnacional das causas e efeitos dos conflitos ambientais, tem levado a graves problemas de acesso à recursos naturais e deslocamento de pessoas que levam muitas vezes à instabilidade social. Os conflitos ambientais são complexos, pois se inter-relacionam com problemas sociais e econômicos e geralmente atingem mais de um grupo de pessoas. Deste modo, os conflitos relacionados ao meio ambiente devem ser preocupação de Estados, organizações e instituições internacionais, sociedade civil, dentre outros.

Esse cenário exige ações concretas de cooperação entre os diversos atores envolvidos na governança ambiental global. Uma temática primordial nesse contexto é a manutenção da paz, que envolve conflitos ambientais. 
O fomento a uma mudança de paradigma em relação à temática de prevenção e resolução de conflitos ambientais, de forma não violenta, é de essencial interesse para o direito internacional. Por isso, a importância de se estudar e identificar ações capazes de estimular os Estados a promoverem mudanças político legislativa efetiva e protetiva ao meio ambiente, que, para sua total implementação, necessita da conscientização da sociedade a respeito da interação entre o meio ambiente, a paz e o desenvolvimento, e ao mesmo tempo fortalecer suas capacidades de conhecimento em prevenção e resolução de conflitos.

Deste modo, o objetivo do artigo é demonstrar a contribuição da mediação ambiental internacional como instrumento adequado de resolução de conflitos ambientais, na busca do desenvolvimento de sociedades mais pacíficas, justas e equilibradas.

No decorrer artigo, primeiramente, falaremos acerca da necessidade humana de compreender a paz, e seu reconhecimento como direito humano, à luz dos estudos de Grotius, Freud e Einstein. Na sequência, indicaremos a relação entre paz, desenvolvimento e meio ambiente, com a análise do princípio 25 da Declaração do Meio Ambiente e Desenvolvimento de 1992.

Por fim, aponta a mediação ambiental internacional como um dos instrumentos de implementação e manutenção do direito a paz ambiental, na medida em que permite a conscientização dos cidadãos acerca da necessidade de se estabelecer mecanismos adequados de redução de conflitos, bem como permite uma emancipação social.

A metodologia do presente trabalho tem por base a teoria crítica dialética, com viés indutivo, visando uma abordagem descritiva, realizada por intermédio de estudo, análise, registro e interpretação dos dados produzidos pelas Organizações das Nações Unidas e obras de referência sobre o tema.

\section{A necessidade humana de compreender a Paz e o Conflito}

A paz e a guerra formam uma intrincada relação que, para bem compreendê-la, nos remete ao início da civilização. Assim é que, na visão de Grotius (2004, p. 71), a “própria guerra nos levará em seguida à paz como a seu último fim”.

Levando-se em conta a importância e a coerência exigidas pelo tema, tomamos a liberdade literária de designar, no presente ensaio, o termo conflito para a palavra guerra. E, então, provocamos a seguinte questão: o conflito é justo? 
A relevância do tema também se coloca diante da importância que esse autor tem para a própria construção do direito internacional e, por consequência, à questão da própria existência e necessidade do conflito. Sabemos que ele não deixará de existir e que os mecanismos tradicionais postos não são capazes para bem resolvê-los, pela própria rigidez de que se revestem e por não envolverem, na tomada de decisões, as partes interessadas.

Para Grotius (2004) os princípios naturais primitivos não são contrários ao conflito. Ao revés, são favoráveis, levando-se em conta que o objetivo do conflito é salvaguardar a conservação da vida e do corpo e de todas as coisas úteis à existência, estabelecendo-se relação harmônica com os princípios primeiros da natureza.

No que atina à reta razão e à natureza da sociedade, Grotius (2004) argumenta que não se proíbe todo o emprego da força, mas apenas as vias de fato, que se contrapõem à vida social, no caso, contra o direito de outrem. Dessa forma, tem-se que o emprego da força não é injusto quando não viola o direito dos outros.

A força seria, então, usada como ultima ratio na resolução de controvérsias, posto que a argumentação é própria do ser humano, e a força, dos brutos. Não é propósito deste ensaio tal descrição minuciosa, senão trazer a percepção retirada de trechos em que se deduz e se reforça, além do exame da existência do conflito, a necessidade de se buscar a pacificação pela mediação desde os primórdios e a construção literária trazida por Grotius que se tornou a base do direito internacional na temática dos conflitos.

Com esse alinhamento, Grotius (2004) desenlaça um fio de argumentos contrários à posição que baliza a justiça do conflito, todos alicerçados sobre deveres do amor ao próximo, caridade, benevolência e paz, trazidos como componentes incompatíveis com o direito do conflito, uma vez que, afastados, dão lugar ao desejo desenfreado dos prazeres, avareza ou mesmo do poder. Na visão de Sêneca, a sociedade não pode subsistir senão pelo amor e pela proteção recíproca das partes de que se constitui.

Nesse sentido, e na busca da proteção ocorreram em 1899 e 1907, as Conferências de Haia para a Paz, por inspiração da opinião pública, ficaram conhecidas oficialmente como Convenções sobre a Resolução Pacífica de Controvérsias Internacionais. Elas tiveram um tiveram um caráter inovador no campo da diplomacia e das relações internacionais, pois foram as primeiras conferências multilaterais a trazer a ideia de um pacifismo ativo, com a finalidade de incentivar a solução pacífica de controvérsias e evitar a guerra (LAFER, s/d). 


\section{A MEDIAÇÃO AMBIENTAL INTERNACIONAL E A INTERAÇÃO ENTRE PAZ, DESENVOLVIMENTO E PROTEÇÃO AMBIENTAL.}

Como evolução do tema, trazemos à lume Freud e Einstein, que desenham a irrupção da natureza humana após a Segunda Guerra Mundial em direção à paz, como um ideal a ser naturalmente perseguido.

São muitas as razões que levam o homem aos conflitos. Einstein e Freud contribuíram de forma intensa para a sua boa compreensão. Isso se deu por meio de diálogos reproduzidos em cartas provenientes do ano de 1932, denominadas “Por que a Guerra” (FADISMA, 2005). E para alinharmos tais diálogos à ideia de conflito desenvolvida até então, também adotaremos a palavra conflito em substituição ao termo guerra.

A troca de correspondências entre Einstein e Freud, no ano de 1932, aborda a maneira de se evitar o conflito. Essas mensagens surgiram em meio à carnificina estabelecida pela guerra das trincheiras, que marcou a primeira Guerra Mundial (1914-1918). Ademais, havia forte presença de armas, como o gás mostarda, e o uso da aviação, além da forte crise econômica que se abateu sobre o capitalismo após a quebra da Bolsa de Nova York, em 1929 (FADISMA, 2005).

Deste modo, Einstein apresenta seu propósito de intenções, por assim dizer, a Freud, com indagação que retrata profundas preocupações de sua mente: existe alguma forma de livrar a humanidade da ameaça de conflito?

Einstein busca em Freud a sugestão de métodos educacionais existentes fora dos objetivos da política, para que, assim, os obstáculos eventualmente estabelecidos sejam afastados. Einstein sugere a Freud a criação de um organismo legislativo e judiciário para arbitrar todo conflito que surja entre as nações. Antevê, todavia, a possibilidade de fortes pressões extrajudiciais às decisões dos tribunais, tributada à fragilidade humana, além de uma grande dificuldade de materializar uma organização supranacional competente para emitir julgamentos de autoridade incontestável (FADISMA, 2005).

Ato contínuo, Einstein desenvolve considerações acerca da necessidade de se obter a segurança internacional, para a qual envolve renúncia à soberania, de difícil concretização. E, nesse âmbito, elenca fatores que paralisam os esforços envidados para tanto, como o intenso desejo de poder e a existência de grupos mercenários que atuam na venda de armas para expansão de seus interesses pessoais.

Outra questão desponta para Einstein e diz respeito ao porquê do homem encerrar dentro de si um desejo de ódio e destruição que parece emergir em circunstâncias anormais, mas que o eleva à potência de psicose coletiva (FADISMA, 2005). 
Diante disso, Einstein encerra as questões por ele formuladas, lançando uma nova, a saber: é possível controlar a evolução da mente do homem, de modo a torná-lo à prova das psicoses do ódio e da destrutividade? Einstein, então, desafia Freud a apresentar o problema da paz mundial sob o enfoque das suas mais recentes descobertas (FADISMA) 2005).

Dessa maneira, Freud concorda com a abordagem de Einstein, mas acrescenta outros ingredientes, de sorte a ampliar, com os seus conhecimentos, as ideias então lançadas. Parte, então, do que considera o ponto de partida das suas investigações: a relação entre o direito e o poder, que passa a designar como direito e violência. Destaca que direito e violência são antíteses, mas apresentam derivação recíproca. Por assim dizer, se retroalimentam (FADISMA, 2005).

Os conflitos de interesses entre os seres humanos, justifica, são resolvidos pelo uso da violência. Com isso, Freud passa a explicar o desenvolvimento da horda humana expondo que, no início de tudo, a força muscular era soberana (violência bruta). Ao depois, ela vem a ser substituída pelo uso das armas e por aqueles que melhor as manejavam. Segue-se a violência apoiada no intelecto. Mas o objetivo da luta ainda permanecia o mesmo. Esse caminho foi modificado no transcurso da evolução; segundo Freud, havia um caminho que se estendia da violência ao direito ou à lei (FADISMA, 2005).

De acordo com Freud, tal caminho encontrava no lema “a união faz a força” sua maior expressão. Mais especificamente, nessa visão, a violência pode ser derrotada, de modo hábil, pela união. E o poder dos que assim se unem representa a lei, que se contrapõe à violência do indivíduo só. A lei passa a ser a força de uma comunidade, mas, ainda assim, a lei é violência (violência da comunidade), posto recair sobre qualquer indivíduo que lhe ofereça oposição (FADISMA, 2005).

Freud, então, lança fios a suas argumentações ao tratar da estabilidade e durabilidade da união da maioria como elementos essenciais à mantença desse estado, por assim dizer, de equilíbrio social. A partir daí, a existência de regulamentos e instituição de autoridades, pela comunidade, torna-se conditio sine qua non para a sua permanência (FADISMA, 2005).

Do reconhecimento dessa identidade de interesses surgem os vínculos emocionais entre aqueles que compõem o grupo, os quais envolvem, necessariamente, sentimentos comuns, que constituem a fonte de sua força. 


\section{A MEDIAÇÃO AMBIENTAL INTERNACIONAL E A INTERAÇÃO ENTRE PAZ, DESENVOLVIMENTO E PROTEÇÃO AMBIENTAL.}

As modificações na lei que permitem exteriorização por meios pacíficos parecem estar na transformação cultural dos membros da comunidade, a única capaz de trabalhar em direção oposta à da violência.

Junto às reflexões anteriormente expostas, o presente diálogo ganha profundidade com a exposição da teoria dos instintos, tecida diante das ponderações realizadas por Einstein a respeito da facilidade que apresentam os homens de se inflamarem pelo ódio e conflito.

Eis a questão: porque as pessoas se revoltam contra o conflito? Por que não o aceitamos como uma de tantas calamidades da vida? Ele próprio responde: porque toda pessoa tem o direito à própria vida. Nessa visão, o conflito põe fim a vidas ávidas de esperanças, compele os homens a matar outros e tudo destrói.

De fato, após Freud envolver-se em um labirinto de ideias que sugerem aparente antagonismo, admite que nos rebelamos contra o conflito porque não podemos fazer outra coisa. Somos pacifistas, por assim dizer, possuímos um atavismo que nos é intrínseco.

O fato é que, em uma visão freudiana, tudo o que estimula o crescimento da civilização opera simultaneamente contra a permanência do conflito (FADISMA, 2005).

Com essa visão, consolida-se a posição segundo a qual a paz estabelece-se como base para alcançar a proteção ambiental relacionada ao desenvolvimento sustentável. Se de um lado, na visão de Grotius (2004), o conflito é justo, de outro, devemos, em cooperação mútua, engajar esforços para alçarmos voos em direção à pacificação, como parte de um projeto humano que tem como base vínculos emocionais apoiados no amor e na identificação de todas as pessoas. Isso implica, por seu turno, compartilhamento de interesses.

O estreitamento de tais vínculos, com efeito, se alinhará em direção contrária à permanência dos conflitos ambientais pelo simples fato de que toda pessoa, segundo enfoque freudiano, tem direito à própria vida.

A mediação, como doravante se examinará, tem aderência com tais propósitos, posto que se propõe a desviar as tendências agressivas das pessoas que influenciam a intensificação dos conflitos ambientais a fim de não encontrar expressão neles. A mediação, destarte, atua com todos os atores envolvidos, fazendo-os se sentir parte de um projeto humano que tem por pilar a sua própria sobrevivência. Esse método se dá por meio de estratégias que permitem a eles desenvolver uma consciência crítica das propostas que integrarão o processo de tomada de decisões. Processo esse que implica prática social global cuja relação é indissociável à 
participação de outros atores como líderes, capazes de provocar um despertar de todos na transformação de comportamentos ambientais.

Segundo Boff (2002), é premente estabelecer a cultura da paz, porque as forças de destruição estão ameaçando o pacto social mínimo, além de toda a biosfera e a continuidade do projeto humano.

Somos seres sociais e cooperativos por essência, com capacidade de afetividade, compaixão, solidariedade e amor. Essas forças, de acordo com Boff (2002), urgem serem usadas para conduzir rumo mais benfazejo à história e conter a violência, como projeto pessoal e coletivo.

Nesse sentido são os esforços da comunidade internacional, que em 2015, como parte da nova Agenda de Desenvolvimento Sustentável, as Nações Unidas adotaram os objetivos do desenvolvimento sustentável (ODS) em substituição aos Objetivos do Milênio. A Agenda 2030, alicerçada na Declaração Universal dos Direitos Humanos e nos tratados internacionais correspondentes, traz objetivos e metas que têm o papel de estimular ações que focam as pessoas, o planeta, a prosperidade, a paz e a parceria (ONU, 2015).

A referida agenda reconhece, ainda, a necessidade de construção de sociedades pacíficas, justas e inclusivas, que ofereçam igualdade de acesso à justiça, fundamentada no respeito aos direitos humanos, incluído aí o direito ao desenvolvimento, o efetivo Estado de Direito e a boa governança em todos os níveis e em instituições transparentes, eficazes e responsáveis (ONU, 2015).

Na mesma linha, a Assembleia Geral, em 2016, aprovou a Resolução 71/189, em que se reconhece a paz como um direito humano. A Declaração relaciona o direito à paz com a promoção e proteção dos direitos humanos e declara, em seus artigos $1^{\circ}$ e $2^{\circ}$, que "todos têm o direito de desfrutar da paz, de modo que todos os direitos humanos sejam promovidos e protegidos e o desenvolvimento seja totalmente realizado (UN, 2016).

\section{O Princípio 25 da Declaração do Rio sobre Meio Ambiente e Desenvolvimento: Paz, Desenvolvimento e Proteção Ambiental}




\section{A MEDIAÇÃO AMBIENTAL INTERNACIONAL E A INTERAÇÃO ENTRE PAZ, DESENVOLVIMENTO E PROTEÇÃO AMBIENTAL.}

A relação entre a paz, o desenvolvimento e a proteção ambiental, na Declaração de Estocolmo, de 1972, não aparece necessariamente nos princípios adotados em Estocolmo, mas é mencionada no parágrafo 6 da primeira parte da Declaração, que estabelece que:

Defender e melhorar o meio ambiente humano para as gerações atuais e futuras se tornou um objetivo fundamental para a humanidade - um objetivo a ser perseguido junto e em harmonia com os objetivos estabelecidos e fundamentais de paz e de desenvolvimento social e econômico mundial (ONU, 1972, n.p.).

Em documentos posteriores, há referência à relação entre a paz ou sua ausência (conflitos), o meio ambiente e o desenvolvimento, mas não são eles abordados em conjunto nesses documentos.

O Relatório Brundtand, de 1987, criado a partir da Comissão Mundial sobre o Meio Ambiente e o Desenvolvimento (WCED), e liderado pela médica norueguesa Gro Harlem Brundtland, abordou as ligações entre paz e desenvolvimento sustentável de forma mais precisa:

Entre os perigos que o meio ambiente enfrenta a possibilidade de uma guerra nuclear, ou de um conflito militar de menor escala envolvendo armas de destruição em massa, é sem dúvida o mais grave. Alguns aspectos das questões sobre a paz e segurança afetam diretamente o conceito do desenvolvimento sustentável. Na realidade, eles são fundamentais (ONU, 1987, n.p.).

No referido relatório, o conflito foi reconhecido como uma causa de desenvolvimento insustentável, particularmente devido às disputas por armas, na medida em que tal disputa apropria-se de recursos humanos e de riqueza que poderiam ser usados para combater o colapso dos sistemas de apoio ambientais, a pobreza e o subdesenvolvimento que juntos contribuem tanto para a insegurança política contemporânea (ONU, 1987, n.p.).

A Declaração de Moscou, adotada no Fórum Global de 1990 sobre o Meio Ambiente e o Desenvolvimento para a Sobrevivência Humana, se referiu à paz como uma condição de desenvolvimento ambiental sólido:

A paz mundial, a participação plena e igual das mulheres e dos homens, a justiça, a eliminação da pobreza e uma determinação para proteger 
nossas crianças das doenças evitáveis e da morte são condições essenciais para um desenvolvimento sustentável e ambiental sólido no nosso mundo interligado (DECLARAÇÃO DE MOSCOU, 1990 apud VIÑUALES, 2014, p. 586).

Enquanto todos esses documentos versam sobre a relação entre a paz, o meio ambiente, e/ou o desenvolvimento, nenhum deles usou precisamente os termos "interdependente e indivisível”, como no Princípio 25 da Declaração do Rio, para se referir às ligações entre esses diferentes conceitos (VIÑUALES, 2014).

O conceito de “paz” estabelecido no Princípio 25 pode ser ligado às relações amistosas, aos direitos iguais, à autodeterminação ou à ausência de violência. Trata-se de um conceito vago.

Na Declaração do Rio não se adotou uma abordagem voltada aos direitos humanos. No contexto da Declaração do Rio e no final da Guerra Fria, todavia, o conceito de paz procurou integrar condições mais amplas de desenvolvimento social, mantendo contornos difíceis de serem delineados (VIÑUALES, 2014).

O Conselho de Segurança da ONU, em 1992, oferece uma visão útil à concepção de paz:

A ausência de guerra e de conflitos militares entre os Estados não garante por si só a paz e a segurança internacional. As fontes nãomilitares de instabilidade nos campos econômicos, sociais, humanitários e ecológicos se tornaram ameaças à paz e à segurança (ONU, 1992, p. 3).

A compreensão das causas estruturais do conflito e das circunstâncias que a permeiam, em constante integração, como a pobreza, a discriminação e a desigualdade de gênero, a degradação ambiental, a marginalização e a desigualdade social e econômica e o conflito armado são conditio sine qua non para tal concepção.

A referência à interdependência e indivisibilidade da paz, do desenvolvimento e da proteção ambiental busca a promoção da igualdade entre eles. Segundo o Princípio 25, a comunidade internacional deve tratá-los do mesmo modo e com a mesma ênfase, devendo tais conceitos serem examinados em conjunto (VIÑUALES, 2014). 


\section{A MEDIAÇÃO AMBIENTAL INTERNACIONAL E A INTERAÇÃO ENTRE PAZ, DESENVOLVIMENTO E PROTEÇÃO AMBIENTAL.}

Quanto ao uso do termo “interdependente”, referenciado no Princípio 25, ao fazer alusão ao entrelaçamento da paz, do desenvolvimento e da proteção ambiental, quer significar que a realização de qualquer um deles requer a efetivação dos outros, apesar de suas particularidades.

No mesmo tom, o conceito de indivisibilidade implica interpretação integrada dos conceitos de paz, desenvolvimento e proteção ambiental.

A natureza do Princípio 25, como regra, reflete muito mais um processo de coordenação e integração. Nessa linha, o referido princípio pode ser compreendido à semelhança de um guia para a integração da paz, do desenvolvimento e da proteção ambiental.

E a utilização da cooperação internacional na aplicação desse princípio mostra-se essencial para a atuação desse concerto na pacificação dos conflitos ambientais.

O conceito de segurança ambiental está entrelaçado à paz e ao desenvolvimento na Declaração do Rio sobre Meio Ambiente e Desenvolvimento, figurando como componente importante para a compreensão do âmbito e do objetivo perseguido pelo Princípio 25.

Com efeito, não há consenso sobre sua definição, mas tem sido descrita como a disponibilidade atual e futura (determinada pelos fatores - oferta, acessibilidade e gestão) de serviços de sustentação da vida de ecossistemas e de produtos de necessidade humana e processos naturais que contribuam com o alivio da pobreza e dissuasão de conflitos (HECKER, 2011).

Nessa definição, pode-se perceber que a segurança ambiental está ligada tanto com a noção de paz (dissuasão de conflitos) quanto com o desenvolvimento (redução da pobreza) (VIÑUALES, 2014). Trata-se de conceito multifacetário.

O Princípio 25, reafirmando as ligações entre a paz, o meio ambiente e o desenvolvimento, é outra expressão do conceito de segurança do meio ambiente. Conforme realça Viñuales (2014), muitas iniciativas de políticas postas em prática para lidar com a segurança ambiental também constituem forma de implantação do referido princípio.

Em geral, a relação entre a paz e o meio ambiente é identificada pela dicotomia dos conflitos. No entanto, a relação pode se expressar pela cooperação ambiental, que conduz à pacificação, ao reunir partes interessadas no conflito para trabalharem de modo a construir a confiança e reduzir tensões políticas, de acordo com o que estabelece o Relatório do Programa das Nações Unidas de 2004 (UNEP, 2004). 
Muito embora a relação conceitual entre a paz e o meio ambiente se encontrar fora da Carta da ONU, desde o início dos anos 90, a prática do Conselho de Segurança da ONU tem expandido na temática da prevenção de conflito. A propósito, o Painel de Alto Escalão sobre Ameaças, Desafios e Mudanças adotou uma abordagem ampla em relação à interpretação do papel do Conselho de Segurança, onde afirma que ele tem pleno poder sob o Capítulo VII da Carta das Nações Unidas para lidar com as ameaças à segurança, cujas as quais os Estados estão preocupados (VIÑUALES, 2014).

O Princípio 25 se engrandece quando focado na conexão que estabelece com os demais princípios da Declaração do Rio sobre Meio Ambiente e Desenvolvimento.

Considerado como uma Declaração de Princípio, o Princípio 25 pertence à categoria dos princípios (da Declaração do Rio) que buscam a promoção e a operacionalização da cooperação e da paz internacional, tal como o Princípio 26, que aborda a resolução pacífica de disputas ambientais.

O Princípio 25 tem forte recorte na seara dos direitos humanos ao tratar do desenvolvimento.

É importante observar que as questões ligadas aos direitos humanos no desenvolvimento têm uma integração explícita limitada, como destacado no processo da Declaração do Rio.

A dimensão humana do desenvolvimento é frequentemente associada com o discurso dos direitos humanos, e trouxe o foco de desenvolvimento para o indivíduo como o beneficiário final. Isso sem dúvida está em sintonia com o Princípio 1 da Declaração do Rio que diz que o beneficiário final é e permanece sendo o "ser humano" mais do que o "meio ambiente” (VIÑUALES, 2014, p. 596, tradução livre).

No entanto, desde os anos 90, o conceito de desenvolvimento se expandiu, de sorte que inclua também as dimensões sociais, de direitos humanos, de boa governança e de democracia.

\section{A mediação ambiental internacional}




\section{A MEDIAÇÃO AMBIENTAL INTERNACIONAL E A INTERAÇÃO ENTRE PAZ, DESENVOLVIMENTO E PROTEÇÃO AMBIENTAL.}

Para Castells (2016) e Bauman (2005, 2001), nosso mundo e nossas vidas estão sendo moldadas pelas tendências conflitantes da globalização e da identidade. A informação, a tecnologia e a reestruturação de capitalismo induziram uma nova forma de sociedade, a sociedade em rede. Essa sociedade é marcada por uma enorme evolução técnica e pela globalização, que provocou muitas mudanças em padrões de socialização e comunicação em conflitos. Em particular, as mudanças na difusão do poder, redes sociais e comunicação criaram novas oportunidades e necessidades para uma gestão bem-sucedida de conflitos.

Todas essas mudanças fazem parte da pós-modernidade ${ }^{1}$, que descontruiu a ideia de centralidade, segurança no Estado, relações verticais por uma ideia de fluidez e de rede de comunicação, relações móveis e horizontais pautadas em diversos saberes na busca de soluções para problemas em constante transformação.

Assim, faz-se necessário identificar mecanismos de resolução de conflito que possam atender a essa fluidez. Para tanto, a mediação ambiental internacional pode contribuir para as necessidades atuais, que é apresentar uma resposta para a questão ambiental, mas que permita a construção de um ambiente de paz.

Deste modo, buscamos orientações da Carta das Nações Unidas, que estabelece à Assembleia Geral a faculdade de recomendar medidas objetivando a resolução pacífica de controvérsias. Algumas Resoluções da Assembleia Geral indicam a necessidade do fortalecimento do papel da mediação na resolução pacífica de controvérsias e prevenção e solução de conflitos (GARCÍA, 2012).

Nessa linha, a Resolução nº 2171/14, do Conselho de Segurança, reitera a necessidade de se adotar um enfoque integrado na prevenção de conflitos e na paz sustentável que compreenda medidas operacionais e estruturais. Esse enfoque tem como objetivo prevenir os conflitos armados e sua abordagem em causas fundamentais, incluindo o fortalecimento do estado de direito, no plano internacional e nacional, um crescimento econômico sustentável, a erradicação da pobreza e o desenvolvimento social, além da boa governança, da igualdade entre os gêneros, o respeito e a proteção dos direitos humanos (ONU, 2014).

\footnotetext{
${ }^{1}$ Para Bauman, em sua obra modernidade e ambivalência, a ideia de pós-modernidade está representada em uma visão fria e crítica da modernidade na sua totalidade, em avaliar o seu desempenho, julgar a solidez e congruência de sua construção. A pós-modernidade para o autor não representa “ o fim, o descrédito ou a rejeição da modernidade”. Trata-se da própria modernidade a se examinar longa, atenta e sobriamente concluindo pela necessidade de mudança. (BAUMAN, 1999, p. 288). Sobre o tema verificar, também, LYOTARD, Jean-François. O pós-moderno. Trad. Ricardo Côrrea Barbosa. 3. ed. Rio de Janeiro: Editora José Olympio, 1988; BAUMAN, Zigmunt. Modernidade Líquida. Trad. Plínio Dentzien. Rio de Janeiro: Editora Jorge Zahar, 2001.
} 
Atualmente, há um movimento crescente no número de conflitos, internos e internacionais, que são dirimidos pelos meios informais de solução de controvérsias, em especial, os bons ofícios e a mediação, ainda que alguns conflitos se desenvolvam em tribunais internacionais, tais como a Corte Internacional de Justiça, o Tribunal Internacional do Direito do Mar, os tribunais especializados em direitos humanos, e, no caso de disputas comerciais e de investimentos por mecanismos estabelecidos pela Organização Mundial de Comércio (OMC).

Certamente, isso se deve ao fato de serem mais flexíveis e suas propostas de solução não obrigarem as partes, podendo elas as aceitarem ou não, em contraposição aos meios herméticos, como a arbitragem e a resolução judicial, que têm caráter obrigatório. Além disso, os bons ofícios e a mediação têm lugar em qualquer momento e em circunstâncias complexas, que são a marca do sistema internacional contemporâneo. Tudo isso, confere a eles grande acolhida no direito internacional (GARCÍA, 2012).

Identificada pelo artigo 33 da Carta das Nações Unidas como um meio de resolução pacífica dos conflitos internacionais, a mediação surge como uma forma de fortalecer a atuação dos atores envolvidos. É um processo através do qual uma terceira parte assiste duas ou mais partes, com seu consentimento, para prevenir, gerir ou resolver um conflito, ajudando as partes a desenvolver mutuamente a aceitação de acordos (ONU, 2017).

Segundo o Manual da ONU sobre Mediação, um processo de mediação eficaz depende da natureza do conflito e da preparação e percepção do mediador ou da equipe de mediadores quanto às causas e a dinâmica do conflito, as posições, os interesses das partes, as necessidades da sociedade em geral, no âmbito regional e internacional (ONU, 2012).

E, nessa perspectiva, cabe aos mediadores e suas equipes proporcionarem uma proteção para as partes em conflito e estabelecerem uma aliança baseada na confiança no processo e na crença de que a resolução pacífica é possível. Um bom mediador promove o intercâmbio por meio da escuta ativa e do diálogo, promove o espírito de colaboração por meio da resolução de problemas, assegura que as partes em negociação têm suficiente conhecimento, informação e habilidades para negociar com confiança, além de ampliar o processo para incluir as partes interessadas de diferentes segmentos de uma sociedade (ONU, 2012).

A mediação tem se mostrado efetiva para a solução de conflitos, para alcançar a paz, tanto entre os Estados como dentro de Estados em conflito. Há um voluntário esforço em se 


\section{A MEDIAÇÃO AMBIENTAL INTERNACIONAL E A INTERAÇÃO ENTRE PAZ, DESENVOLVIMENTO E PROTEÇÃO AMBIENTAL.}

utilizar esse método, e suas técnicas, que varia quanto aos objetivos. Algumas vezes, aborda-se uma específica questão para conter ou gerenciar um conflito, e em outras vezes é necessário abranger um amplo alcance de questões dentro de um compreensivo processo de paz. Tais processos oferecem uma oportunidade crítica para os Estados e sociedades reformularem sua política, segurança e panorama socioeconômico, a fim de estabelecer a base para a paz. (ONU, 2017).

A mediação constitui método baseado nos processos de negociação (STULBERG, 1981) e também é uma forma de resposta facilmente adaptável e sensível ao contexto, que tem por marca a ampliação do processo de negociação para refletir os diferentes conflitos, participantes e situações (BERCOVITCH, 2016).

Para Moore (1998), quaisquer que sejam as suas características específicas, a mediação deve, no essencial, ser vista como uma extensão do processo de negociação através do qual um terceiro, aceito pelas partes, intervém para alterar o curso ou o resultado de um determinado conflito. O terceiro, sem poder de decisão autoritário, tem a função de ajudar os disputantes na busca de um acordo mutuamente aceitável. Como forma de gestão de conflitos, a mediação é distinguível das formas mais vinculativas de intervenção de terceiros, tais como a arbitragem e a adjudicação, na medida em que é iniciada a pedido dos conflitantes. Assim, é voluntária e deixa o poder decisório na mão dos conflitantes.

A intervenção de uma terceira pessoa profissional no processo de mediação e a responsabilidade das partes na adoção das decisões são notas características de todas as definições que delineiam a mediação. Às partes pertence o protagonismo absoluto na tomada de decisões, cabendo ao mediador a organização e condução do procedimento. Nessa dinâmica, o mediador simplesmente auxilia, colabora para que as partes cheguem a uma solução, mas de um modo imparcial e ativo (JOSÉ, 2006).

O processo de mediação possui características particulares, dentre as quais constitui uma extensão e uma continuação da gestão pacífica de conflitos, quando os mediadores atuam em um conflito, seja interno ou internacional, o fazem para afetá-lo, mudá-lo, resolvê-lo, modificá-lo ou influenciá-lo de algum modo, constituindo tal aspecto outra característica marcante (BERCOVITCH, 2016).

A mediação internacional é examinada sob vários ângulos, que incluem desde pesquisas acadêmicas a recomendações políticas, passando por desenvolvimento de teorias a esse respeito, sendo certo que quatro principais tradições se formaram nesse estudo. Assim, o 
primeiro grupo de estudos tem, majoritariamente, nos acadêmicos associados ao Programa de Negociação da Universidade de Harvard, suas bases, oferecendo como contribuição o aconselhamento sobre o que constitui a boa gestão de conflitos em situações reais (BERCOVITCH, 2016). Fisher, Ury e Patton (2005) destacam-se, nesse segmento, com livros e manuais sobre como mediadores e negociadores devem se comportar, o que define uma boa negociação ou mediação e como os conflitos podem ser resolvidos, tendo na obra "Getting to Yes” (1981) seu exemplo melhor.

O segundo grupo apresenta como contribuição o desenvolvimento de um conjunto de regras aplicáveis a todos os conflitos, nacionais e internacionais, utilizando-se de técnicas variadas de interação e resolução de problemas, em uma combinação da ação política com a experimentação científica. O referido grupo, que tem nas figuras de Burton e Doob, entre outros $^{2}$, sua grande referência, tem por suporte noções teóricas e a experiência de acadêmicos.

Pesquisas realizadas por economistas e seguidores da Teoria dos Jogos, que desenvolvem modelos matemáticos para examinar como pessoas se comportam em situações de conflitos cujas condições são de racionalidade e informações ótimas, formam o terceiro grupo. O exame de estratégias para realizar concessões e alcançar acordos são práticas comuns desses estudos ${ }^{3}$.

O quarto grupo é representado por descrições e investigações empíricas de casos de mediação, que buscam desenvolver teorias e oferecer linhas gerais de ação por meio de descrição detalhada de um caso particular de mediação internacional, experimentos de laboratório voltados para mediação e estudos quantitativos que compreendem variados casos de mediação internacional. O objetivo desse grupo é o de formular e testar proposições sobre sua efetividade, bem como aferir condições sob as quais a mediação pode obter melhor desempenho. Esse grupo produziu as mais importantes recomendações políticas para os tomadores de decisão (BERCOVITCH, 2016).

A base da mediação ambiental internacional se localiza na intersecção de três áreas, a saber: relações internacionais, resolução de conflito e estudos ambientais, afirmam Shmuelli e

\footnotetext{
2 Para melhor aprofundamento, a leitura das obras de John W. Burton, como Global Conflict. Brighton: Wheatsheaf, 1984, e de L.W. Doob, como Resolving Conflicts in Africa. New Haven: Yale University Press, 1971, são instrumentos valiosos.

3 Para melhor aprofundar, a obra de H. Raiffa, denominada The Art and Science of Negotiation. Cambridge: Harvard Universitiy Press, 1982, constitui boa referência.
} 


\section{A MEDIAÇÃO AMBIENTAL INTERNACIONAL E A INTERAÇÃO ENTRE PAZ, DESENVOLVIMENTO E PROTEÇÃO AMBIENTAL.}

Vranesky (2016) ${ }^{4}$. Em geral, a resolução de um conflito ambiental internacional pode começar pela diplomacia. Inicialmente, é executada por uma estrutura oficial, porém com muitas dificuldades, pois a gestão e a legislação ambiental requerem processos de coordenação complexos, que, na esfera internacional, tornam-se ainda mais complicados por conta da multiplicidade de governos, com variados graus de comprometimento em relação ao problema ambiental.

Desse modo, vem ganhando espaço a diplomacia privada, que se utiliza de medidores extraoficiais (indivíduos, organizações não governamentais etc.) para executar atividades de mediação, ampliando o âmbito de atuação e participação no processo de mediação.

No sistema internacional moderno, dada a complexidade do ambiente internacional, junto aos Estados, surge crescente número de organizações internacionais e transacionais que atuam e influenciam questões afetas à paz e às guerras e que também têm participação ativa na resolução de conflitos internacionais. Entre as organizações internacionais, estão a Organização dos Estados Americanos (OEA) e a Organização das Nações Unidas (ONU), que representam Estados e têm expressiva atuação na mediação formal. Já as organizações transnacionais, como a Anistia Internacional, representam indivíduos de diferentes países e têm frequente a prática da mediação informal.

A ONU tem pujança entre as organizações internacionais, especialmente no papel que desempenha na negociação e mediação. Com efeito, a Agenda para a Paz, subscrita pelo secretário-geral Boutros-Ghali, reforça a primazia do emprego da diplomacia preventiva, da promoção e da consolidação da paz para a Organização (ONU, 2017). Reconhece, diante das várias demandas existentes, a necessidade de descentralização e delegação, para que todas as partes da organização sejam utilizadas em sua capacidade plena. Nessa ótica, a ONU deve encorajar as organizações regionais a auxiliarem as Nações Unidas, e o secretário-geral a estimular arranjos ad hoc que darão suporte aos seus esforços, por meio de grupos informais como Os Amigos do Secretário-Geral de Salvador. Igualmente, a ONU pode buscar o envolvimento mais ativo de agentes sem vínculos com o Estado (BOUTROS-GHALI, 2012).

O uso da mediação é amplamente defendido pela Organização das Nações Unidas como meios de prevenção de conflitos, inclusive através da Unidade de Apoio à Mediação,

\footnotetext{
${ }^{4} \mathrm{O}$ texto das referidas autoras foi publicado originalmente no livro Resolving International Conflicts: The Theory and Practice of International Mediation, organizado por Jacob Bercovitch, Boulder CO: Lynne Rienner, 1996. p. 191-215.
} 
vinculada ao Departamento de Assuntos Políticos (MSU). Na esfera doméstica, alguns países ${ }^{5}$ já aplicam a mediação aos conflitos ambientais, principalmente os Estados Unidos, onde as disputas judiciais são demoradas e caras e ainda incentivam detalhes jurídicos e técnicos, em vez das questões subjacentes. Os principais pesquisadores na temática ambiental apoiam um processo construtivo e colaborativo.

Na resolução de conflitos, por meio da mediação, as tarefas na construção de soluções podem ser divididas em vários níveis e agentes. Muitas vezes são diversos os setores afetados pelo conflito, o que exige um número maior de pessoas envolvidas na sua resolução. Os mediadores podem atuar em campo, diretamente na fonte do conflito; outros podem atuar em uma esfera mais política, mas essa atuação deve ser interdependente e complementar em busca de soluções construtivas que atendam ao interesse de todos, assim o meio de trabalho e a responsabilidade de cada mediador deverá contribuir para um objetivo comum.

Deste modo, a mediação ambiental internacional desponta como ferramenta de prevenção, construção e manutenção da paz, a ser utilizada principalmente pelos Estados, dada as suas características de incentivo ao diálogo, ao processo participativo, ao estímulo à cooperação, à solidariedade entre os povos e principalmente à possibilidade dos mediadores atuarem em vários níveis do conflito, formando uma rede de pacificadores.

\section{Conclusão}

A paz, ao longo dos anos, enfrentou e foi influenciada pelos movimentos históricos, em especial a Segunda Guerra Mundial, o que repercutiu na produção de documentos internacionais acerca do direito a paz, tendo a Organização das Nações Unidas papel ímpar para tanto.

Consolida-se a compreensão segundo a qual a paz estabelece-se como base para alcançar a proteção ambiental relacionada ao desenvolvimento sustentável. Assim, devemos em cooperação mútua, engajar esforços para alçarmos voos em direção à pacificação, como parte 


\section{A MEDIAÇÃO AMBIENTAL INTERNACIONAL E A INTERAÇÃO ENTRE PAZ, DESENVOLVIMENTO E PROTEÇÃO AMBIENTAL.}

de um projeto humano que tem como base vínculos emocionais apoiados no amor e na identificação de todas as pessoas.

Considerando o desenvolvimento sustentável como resultante da conjugação de três componentes, a saber, o desenvolvimento econômico, social e o meio ambiente, tem ele relação indissociável com a paz, uma vez que sem desenvolvimento não há paz e, sem ela, também não se alcançará esse desenvolvimento.

E o Princípio 25 da Declaração do Meio Ambiente e Desenvolvimento reflete esse processo de coordenação e integração, tendo na cooperação internacional suas bases para a pacificação dos conflitos ambientais.

Nessa melodia, por assim dizer, do Princípio 25, harmoniza-se a segurança ambiental, que, ao seu turno, entrelaça-se aos conceitos de paz e desenvolvimento.

Na pós-modernidade, que tem na fluidez sua marca, as relações entre as pessoas encontram-se em constante mutação, exigindo novas fórmulas para o enfrentamento dos conflitos ambientais, e a mediação mostra-se consentânea a esses movimentos. Isso porque, constitui uma forma de resposta facilmente adaptável e sensível ao contexto, que é capaz de diagnosticar e tratar os diferentes conflitos e situações existentes, além de envolver os participantes no processo de tomada de decisões que promovam a interação entre paz, meio ambiente e desenvolvimento.

\section{Referências}

BAUMAN, Zygmunt. Modernidade Líquida. Trad. Plínio Dentzien. Rio de janeiro: Zahar, 2001.

Identidade: entrevista a Benedetto Vechi. Trad. Carlos Alberto Medeiros. Rio de Janeiro: Zahar, 2005.

BOFF, L. A cultura da paz. 2002. Disponível em: <www.leonardoboff.eco.br/site/vista/20012002/culturapaz.htm>. Acesso em: 24 mar. 2018.

BOUTROS-GHALI, B. ONU: uma agenda para o desenvolvimento. 2012. Disponível em: <http://www.iea.usp.br/publicacoes/textos/boutros_ghalionu.pdf.> Acesso em: 10 fev. 2018.

BURTON, J. W. Global Conflict. Brighton: Wheatsheaf, 1984.

CASTELLS, Manuel. A sociedade em rede: A era da informação: economia, sociedade e cultura. Trad. Roneide Venancio Majer.17 ed., rev. e ampl., v.1. São Paulo: Paz e Terra, 2016. 
FADISMA - Faculdade de Direito de Santa Maria. Um diálogo entre Einstein e Freud: por que a guerra? Apresentação de Deisy de Freitas Ventura e Ricardo Antônio Silva Seitenfus. Santa Maria: FADISMA, 2005.

FISHER, R.; URY, W.; PATTON, B. Como chegar ao sim: negociação de acordos sem concessões. Tradução: Vera Ribeiro e Ana Luiza Borges. 2. ed. rev. ampl. Rio de Janeiro: Imago, 2005.

GARCÍA, A. Mediación y Solución de Controversias En El Sistema internacional Contemporáneo. In: CINU BOGOTÁ- MINISTERIO DE RELACIONES EXTERIORES. Diplomacia Preventiva: recuperando el Capítulo VI de la Carta de las Naciones Unidas. Colombia, 2012.

GROTIUS, Hugo. O direito da guerra e da paz. Tradução: Ciro Mioranza. Ijuí: Unijuí, v.1, 2004. Coleção clássicos do direito internacional.

HECKER, J. H. Peace and sustainable development through environmental security: a methodology for environmental security assessments. The Hague: Institute for Environmental Security, 2011.2 Disponível em: $<$ http://www.envirosecurity.org/espa/PDF/IES_ESPA_ESA_Methodology.pdf>. Acesso em: 28 fev. 2018.

JOSÉ, M. J. C.S. La Mediación como Mecanismo extrajudicial de solución de los conflictos familiares. In: ARAMAYO, M. S. V. (Coord.). Introducción al derecho Del Arbitraje y Mediación. Ratio Legis Librería Jurídica, Salamanca, 2006. p. 267-298.

LAFER, Celso. Conferências da Paz de Haia (1899 e 1907). Disponível em: $<$ http://cpdoc.fgv.br/sites/default/files/verbetes/primeirarepublica/CONFER\%C3\%8ANCIAS\%20DA\%20PAZ\%20DE\%20HAIA.pdf>. Acesso em 30 de mar de 2018.

LYOTARD, Jean-François. O pós-moderno. Trad. Ricardo Côrrea Barbosa. 3. ed. Rio de Janeiro: Editora José Olympio, 1988.

MOORE, C. W. The mediation process: pratical strategies for resolving conflicts. São Francisco: Jossey-Bass, 1986.

ONU - Organização das Nações Unidas. Declaração de Estocolmo. 1972. Disponível em: http://www.direitoshumanos.usp.br/index.php/Meio-Ambiente/declaracao-de-estocolmosobre-o-ambiente-humano.html. Acesso em: 29 mar. 2018.

Organização das Nações Unidas. Relatório da comissão mundial sobre meio ambiente e desenvolvimento: nosso futuro comum. 1987. Disponível em: <http://www.undocuments.net/our-common-future.pdf>. Acesso em: 1 mar. 2018. 


\section{A MEDIAÇÃO AMBIENTAL INTERNACIONAL E A INTERAÇÃO ENTRE PAZ, DESENVOLVIMENTO E PROTEÇÃO AMBIENTAL.}

. Organização das Nações Unidas. Departamento de Assuntos Políticos. United Nations Guidance for Effective Mediation. jul. 2012. Disponível em: <http://peacemaker.un.org/guidance-effective-mediation>. Acesso em: 2 mar. 2018.

Organização das Nações Unidas. Departamento de Assuntos Políticos (DPA). Guidance on Gender and Inclusive Mediation Strategies. 2017. Coordination: Pouran Ghaffarpour. UNION, Publishing Services Section/ Nairobi. Disponível em: $<$ http://peacemaker,un.org.node/2940>. Acesso em: 16 mar. 2018.

Declaration on the Right to Peace. Resolution adopted by the General Assembly. A/RES/71/189. 2016.2 Disponível em: <http://www.un.org/en/ga/search/view_doc.asp?symbol=A/RES/71/189>. Acesso em 02 de fevereiro de 2018.

STULBERG, J. B. The Theory and pratice of mediation: a reply to professor Susskind. Vermont Law Review, [S.l], v. 6, n.1, p. 85-117, 1981.

UNEP - UNITED NATIONS ENVIRONMENT PROGRAMME. Understanding environment, conflict, and cooperation. Nairobi: DEWA, 2004. Disponível em: $<$ http://wedocs.unep.org/bitstream/handle/20.500.11822/8684/-

Understanding\%20Environment\%2c\%20Conflict\%20and\%20Cooperation2004424.pdf?sequence=3\&isAllowed=y> . Acesso em: 1 mar. 2018.

VIÑUALES, J. E. The Rio declaration on environment and development: preliminary study. In: VIÑUALES, J. E. (Ed.). The Rio declaration on environment and development: a commentary. Reino Unido: Oxford University Press, 2014. p. 1-60. 